\author{
Marquette University \\ e-Publications@Marquette
}

2012

\title{
Transformative Education in a Broken World: Feminist and Jesuit Pedagogy on the Importance of Context
}

Theresa Weynand Tobin

Marquette University, theresa.tobin@marquette.edu

Follow this and additional works at: https://epublications.marquette.edu/phil_fac

Part of the Philosophy Commons

\section{Recommended Citation}

Tobin, Theresa Weynand, "Transformative Education in a Broken World: Feminist and Jesuit Pedagogy on the Importance of Context" (2012). Philosophy Faculty Research and Publications. 642.

https://epublications.marquette.edu/phil_fac/642 
Transformative Education in a Broken World: Feminist and Jesuit Pedagogy on the Importance of Context

\section{University Press Scholarship Online \\ Fordham Scholarship Online}

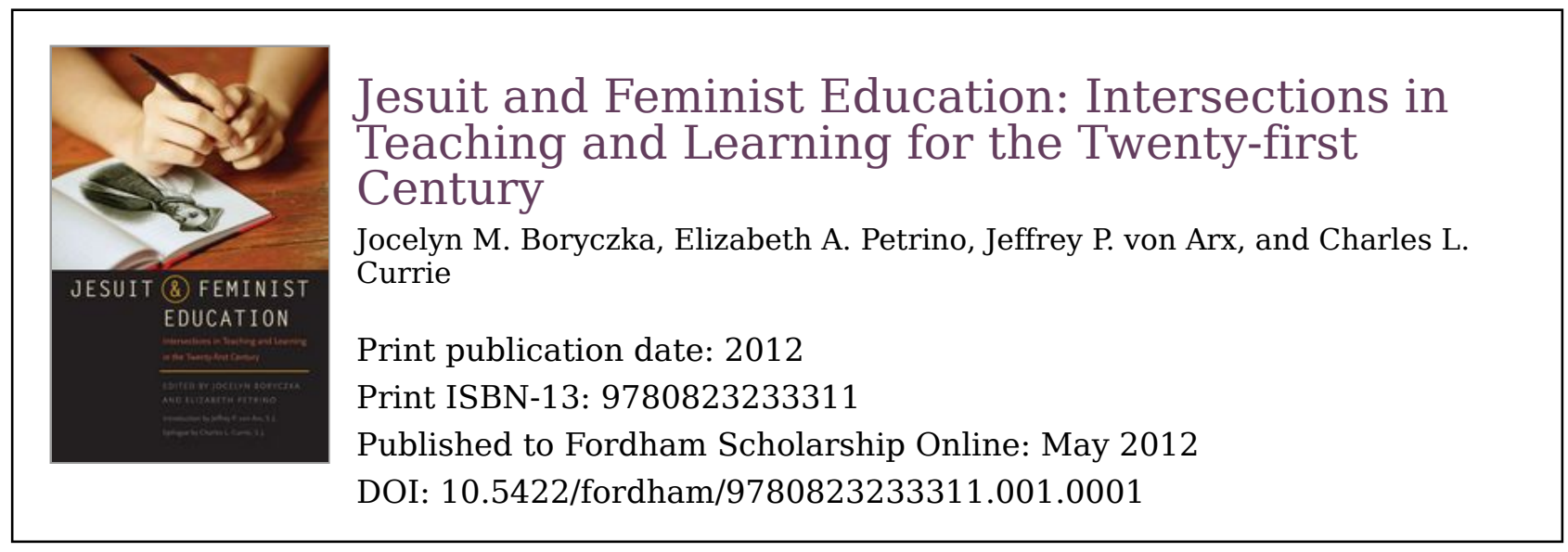

Transformative Education in a Broken World: Feminist and Jesuit Pedagogy on the Importance of Context

Theresa Weynand Tobin

DOI:10.5422/fordham/9780823233311.003.0010

\section{[-] Abstract and Keywords}

This chapter relates the concept of positionality from feminist theory and pedagogy to the Ignatian paradigm to show how its focus on the individual, at the expense of the structural, fails to acknowledge the unequal power relationships that disadvantage students from minority groups. Focusing on the positionality of gay and lesbian students in the author's classroom at a Jesuit college, it explores how becoming attentive to our own positions with respect to our students allows us better to examine how relationships of domination and subordination between members of oppressed and privileged groups in larger social and ecclesial contexts are re-created at the micro-level in the classroom.

Keywords: positionality, feminist theory, pedagogy, inequality, power relationships, minority groups, gay students, lesbian studies

In a recent ethics class, my students and I were discussing the Civil Rights Act, in particular Title VII, on equal employment opportunity. This portion of the Civil Rights Act makes it illegal to discriminate in employment practices on the basis of race, color, religion, national origin, or sex. The class was considering whether or not sexual orientation ought to be added to the list. In some places it remains legal to fire someone simply because of his or her sexual orientation. We were considering whether or not this is fair and consistent with a principled commitment to the moral equality of all human beings. The discussion was proceeding fairly well, with some differences of opinion being expressed in a respectful manner, until one young man raised his hand and made the following comment: "We should not protect homosexual persons from discrimination because homosexuals are pedophiles, and we don't think we should protect them, right?" There were some audible gasps of shock among other students at this young man's 
Transformative Education in a Broken World: Feminist and Jesuit Pedagogy on the Importance of Context

comment, but the most dramatic response came from a openly gay young woman who spent the rest of the class in tears-angry, offended, and deeply hurt by this remark.

\section{What Went Wrong?}

As the instructor, I was really upset by this experience, in large part because a student got hurt in my classroom. I was seriously concerned about the pain that this young woman had endured and the breach of trust that had occurred in our classroom community. One of the central goals of philosophy is to teach students critical thinking skills, and so many people with whom I consulted about the experience commented that perhaps it was a "teachable moment," an opportunity to critically interrogate this line of reasoning as a class. While I am sympathetic to (p.162) this view, this experience raised difficult questions for me about how to balance the goal of critical thinking about socially relevant topics with a genuine respect for each of our students, especially when the topics we discuss may touch the personal lives, indeed the very identities, of our students.

At the outset of the course, I had explained to my students that we would periodically be discussing socially relevant and contentious topics in this class. We had worked extremely hard to build a safe classroom environment where all students would feel comfortable sharing their views. I had stressed that listening to opposing viewpoints is an essential part of the process of growing in moral wisdom. I had also stressed repeatedly that we live out cura personalis in the classroom by treating each other with dignity and respect, especially when expressing opposing viewpoints. Up to this point, classroom discourse had been going quite well. What went wrong?

Recent work in feminist pedagogy helped me diagnose the problem as a failure to attend to a particular aspect of the learning context that feminists call positionality. ${ }^{1}$ Part of what went wrong in my class was a failure to consider the ways in which the context of the teaching and learning environment, in particular the heteronormative and heterosexist features of that context, was influencing not only individual students' perceptions, beliefs, and intuitions but also relationships of relative power and privilege among students. The social structures that continue to marginalize gay men and lesbians were replicated at the micro-level in my classroom, locating the straight male in a relative position of power and authority in relation to the gay female. By considering only the ways in which social context influences my students as individuals, I was failing to account for the unequal social relations both within and outside the classroom that continue to disadvantage those students who are members of marginalized groups and to inhibit the goal of transformative education, a goal toward which both feminist and Jesuit pedagogy aim. While feminist and Jesuit pedagogy both emphasize the importance of context, feminists pay special attention to the ways in which context affects relationships among students. In this chapter, I explore the ways in which a feminist emphasis on positional-ity can enrich Jesuit pedagogy and facilitate the goal of transformative education.

\section{(p.163) Jesuit Pedagogy on the Importance of Context}

One expression of the Jesuit commitment to transformative education is the graduation of "men and women of competence, conscience and compassion, seeking ... to enhance the quality of people's lives, particularly among God's poor, oppressed and neglected." ${ }^{2}$ While I remain deeply committed to this ideal, my recent classroom experience prompted difficult questions about how to achieve the goal of transformative education in a non-ideal setting, namely, a classroom context that is itself shaped by the kinds of injustices we aim to combat. One of the Ignatian paradigm's central concepts for education is attention to the context within which teaching and learning take place. Like all aspects of Ignatian pedagogy, the emphasis on context derives from 
Transformative Education in a Broken World: Feminist and Jesuit Pedagogy on the Importance of Context

the Spiritual Exercises. Ignatius believed that spiritual direction would not be fruitful if the director did not first get to know, as well as possible, the retreatant's predisposition to prayer and to God. He emphasized that a person's life experience, the real-world context within which the individual is situated and that influences his or her beliefs, perceptions, values, and relationships, should determine the shape and content of the spiritual exercises that are used. ${ }^{3}$ Similarly, Jesuit education, which aims to be transformative, requires that teachers become as familiar as possible with the life experiences of their students, that we "meet them where they are," and that we be attentive to the real-world context within which teaching and learning take place. Attention to context means accounting for the influence of "family, peers, social situations, the educational institution itself, cultural climate, the ecclesial situation, media, music and other realities," all of which have an impact on students, for better or worse. ${ }^{4}$

Ignatian pedagogy stresses at least four levels of context that we must consider: the larger social context, current ecclesial context, institutional context of our particular university or college, and context of our individual classrooms. These levels of context are distinct but intimately related and in any particular instance they may be either mutually reinforcing or in tension with one another. First, attention to context requires that we understand as well as possible the socioeconomic, political, and cultural aspects of the larger social context. What's going on in contemporary American life, in politics and pop culture? (p.164) What are the nationwide disparities between rich and poor, and from which socioeconomic classes do our students come? Do they come from relative privilege or poverty, and how might these factors affect any particular student's learning experience? A student's socioeconomic background may, for example, influence her expectations about academic success, or a particular political environment may make freedom of expression about certain topics difficult for some students. ${ }^{5}$

Additionally we must account for the institutional environment of our particular university or college as both Jesuit and Catholic. We need to be familiar with the complex networks of norms and expectations within the university setting, the culture of teaching and learning that our particular Jesuit institution promotes. Is it an environment that promotes trust and respect for others despite differences of opinion? Moreover, what is the ecclesial situation at the present time and how might this influence the learning ethos of our particular institution as Catholic and as likely serving a large number of Catholic students? Finally, attention to context requires awareness of the ways in which each of these levels of context shapes the beliefs, values, concepts, and perceptions that students bring to the start of the learning process in our individual classrooms.

One aspect of context that helps make sense of what happened in my classroom is the heteronormativity and heterosexism influential at every level: the larger social context of American culture, current ecclesial context of the Catholic Church, institutional setting of my particular university, and individual classroom in which this incident occurred. The term "heteronormative," refers to the idea that sexual and marital relations are normal only when they involve two persons, one of each sex; and that heterosexuality is the only normal sexual orientation. "Heterosexism" here refers to various forms of bias, prejudice, and discrimination against persons who are not exclusively heterosexual. Much like racism and sexism, heterosexism can be more or less overt, and it can manifest either at the level of individuals in interpersonal relations or at the level of institutions in either formal rules and policies or informal social norms and expectations. ${ }^{6}$ While an individual can behave in a heterosexist manner (in much the same way that an individual can behave in a racist manner), heterosexism does not necessarily reflect one individual's malicious intent to harm (p.165) another person. 
Transformative Education in a Broken World: Feminist and Jesuit Pedagogy on the Importance of Context

Rather, it often refers to systemic and structural prejudice that generates and maintains oppression in a myriad of ways, ranging from job discrimination to harassment, political disempowerment, and brutal and life-threatening hate crimes.

Heteronormativity and heterosexism are logically distinct concepts. That is, heteronormativity does not logically entail heterosexism. However, in reality they are often closely linked: In a context governed by heteronormativity, people tend to produce and replicate political, economic, and moral structures that are heterosexist. One reason for this is that what is considered normal functions not just as a term describing how most people allegedly are but also as a prescriptive term setting a moral and cultural standard and leading people to treat those who deviate from this standard as deviants (and so as inferior, less than, threatening, morally corrupt), rather than just different. Despite an increase in the more visible presence of gays and lesbians and relationships in American pop culture, for example, in TV shows such as Will and Grace or movies such as Brokeback Mountain, heteronormativity and heterosexism continue to shape the larger social context of American life. One can see this in political disputes over gay marriage, in general public disapproval of and disgust at public figures who "turn out" to be gay, in pronouncements by prominent religious leaders condemning gays and lesbians as moral abominations, in resistance by many people to even consider protecting gays and lesbians from various forms of discrimination, such as job discrimination, and in the preponderance of hate crimes perpetrated against gays and lesbians.

Moreover, with respect to the current ecclesial situation, though some Church leaders condemn heterosexism, heteronormativity is the very foundation of Catholic moral teaching about sexual identity and norms about what constitutes morally permissible sexual relationships. ${ }^{7}$ And though the Church hierarchy does not draw an explicit connection between homosexuality and pedophilia, they have sometimes implied a connection in their response to the scandal of sexual abuse in the Church by banning gay men from entering the seminary. ${ }^{8}$

In such a context, it is no surprise that some of my students hold the view that homosexuality is a perversion and that gays and lesbians are sexual deviants who cannot be trusted and who, like pedophiles, do (p.166) not deserve the same civil protections that the rest of us enjoy. However, Jesuit emphasis on the importance of context prompted deeper reflection on my part about how deeply entrenched heteronormativity is, and about just how much our students unreflectively absorb and perpetuate the heterosexism they see in the media and in the words and deeds of political figures, religious leaders, their parents, and their peers. Moreover, given that sexual orientation is not necessarily a "visible" identity, attention to context requires a heightened awareness of the possibility that diversity in the classroom may include diversity in sexual orientation and that discussions of topics that touch on this issue may evoke strong feelings and touch very deeply and personally the lives of some of our students.

This does not mean that we ought to avoid these topics. Graduating men and women who are ready, willing, and able to work toward a more just world requires tackling in the classroom the most blatant forms of injustice present in the world. What attention to context requires is that we create a classroom environment that is conscious of the contextual factors that shape people's identities and beliefs, and that we tread carefully and perhaps delicately in conversations that are so important but also may be so personal for some students. 
Transformative Education in a Broken World: Feminist and Jesuit Pedagogy on the Importance of Context

While I wholeheartedly endorse the Ignatian emphasis on context as the starting point for transformative teaching and learning, I believe the Ignatian model remains somewhat limited in its ability to capture accurately what happened in my classroom and to generate adequate pedagogical responses to these sorts of incidents. As I understand it, attention to context is essentially about attention to identity. The call to know who our students are and where they are coming from is a call to know, as well as possible, the particular identities of our students as they are shaped by the various levels of context, and to allow these identities to inform as much as possible what we teach and how we teach it. Yet there are different ways of understanding the nature of identity. The Ignatian approach stresses how context at both the micro-and macrolevels may affect the beliefs, attitudes, perceptions, and intuition of each student considered as an individual. While this approach is worthwhile, its failure to highlight the way that context shapes relationships among students, and to address how relational aspects of identity limit its effectiveness. I now examine how feminist pedagogy (p.167) can enrich Jesuit approaches to education and facilitate the goal of transformative education.

\section{Feminist Pedagogy on Positionality}

Feminist and Jesuit pedagogy overlap in many ways. Both view education as a transformative enterprise aimed at graduating men and women who are intellectually, emotionally, and morally prepared to work toward establishing a more just world. Both approaches also stress that transforming the world must start with personal transformation, and that personal transformation cannot happen without attention to context. As bell hooks comments about her teaching, "Whether a class is large or small, I try to talk with all students individually or in small groups so that I have a sense of their needs. How can we transform consciousness if we do not have some sense of where the students are intellectually, psychically?"9 Nonetheless, despite the significant overlap, feminist and Jesuit approaches diverge in how they understand the nature of identity.

Ignatian pedagogy clearly recognizes that social context is relevant to an individual's identity formation. This is precisely why we need to understand the various contexts our students inhabit. However, the Jesuit model tends to presuppose a conception of the student that makes his or her identity a function of a particular set of characteristics that attach to the student as an individual. On this model, the classroom is viewed as a collection of equally situated individuals, each of whom may have a unique set of beliefs and values shaped by the social and cultural contexts he or she inhabits. The Ignatian emphasis on identity directs us to approach our students on an individual basis. When I attend to context, I attend to the ways in which various levels of context shape and affect my students qua individuals.

In contrast, feminists understand identity not as a fixed set of characteristics that an individual has but as relational and shifting, depending on context. The feminist conception of relational identity has its roots in feminist ethics, beginning most notably with Carol Gilligan's groundbreaking work on moral development, In a Different Voice, which gave rise to what is known as the ethics of care. The ethics of care emerged initially as a feminist response to a long history of claims in Western (p.168) philosophy and psychology that women's moral capacities are inferior to men's capacities and that women are somehow less capable than men of moral maturity and development. Gilligan purports to demonstrate that women are not morally deficient, but rather that they often view moral problems from a different perspective, or in a "different voice," which she called a care perspective. ${ }^{10}$ The justice perspective associated with the dominant moral paradigms of modern Western philosophy and society emphasizes independent, self-sufficient, discrete individuals who resolve moral dilemmas by applying 
Transformative Education in a Broken World: Feminist and Jesuit Pedagogy on the Importance of Context

abstract universal moral rules or principles. Gilligan found that the women she interviewed tended instead to emphasize the moral salience of relationships, to highlight the moral significance of dependence and interdependence, and to promote the moral value of care. ${ }^{11}$

While the ethics of care focuses on interpersonal relationships, more recent feminist work shows the significance of relational aspects of selfhood and identity for political and structural contexts. ${ }^{12}$ For example, Iris Marion Young draws on Stephen Epstein's understanding of identity as "a socialized sense of individuality. ... Identity is constituted relationally, through involvement with-and incorporation of-significant others and integration into communities."13 According to Young, some of the most salient aspects of an individual's identity result from his or her membership in certain social groups and from interactions among social groups. Young distinguishes social groups from aggregates and associations. Grouping people on the basis of their zip code might be an aggregate. Examples of associations include neighborhood or parent organizations and religious groups. Social groups differ from aggregates in that they are more than just a mere collection or grouping of people based on some arbitrary shared feature or trait. ${ }^{14}$ Social groups then differ from associations in that they are not formally organized institutions that people independently and freely choose to join. As Young notes, social groups differ from these in that "one finds oneself as a member of a group, whose existence and relations one experiences as always already having been. For a person's identity is defined in relation to how others identify him or her, and they do so in terms of specific attributes, stereotypes, and norms associated with them, in reference to which a person's identity will be formed." ${ }^{15}$ In Young's analysis, social identity is a function of social relations. Identity (p.169) is not simply a matter of how context influences the beliefs, values, and capacities an individual has; it is also a result of how others perceive and treat the person and how he or she perceives him- or herself in relation to others. These variable perceptions are mitigated in large part by social group membership and relations.

Most important, for our purposes, feminists emphasize relational aspects of identity as absolutely essential for understanding the nature of oppression. Characterizing the nature of identity as relational rather than individualistic allows us to see how oppression and privilege are also relational. Laurie Finke, a professor of women's studies and gender studies at Kenyon College, draws on Julia Kristeva's work to explain this idea to her students. Finke notes, "What we need is a description that is not based on categories but, as Kristeva says, on positionality, on relations. No group is in and of itself oppressed or marginal. It is only in relation to something else. So ... for instance, we can say that women are marginal compared to men. But Black women are marginal compared to white, middle class women. What is perceived as marginal at any given time depends on the position one occupies." ${ }^{16}$ On this view, identity, and whether or not one is oppressed or privileged in particular contexts as a result of her identity, is a matter of not merely the beliefs and attitudes an individual has but also her social position relative to others.

Starting from a relational rather than individualistic understanding of identity, feminists emphasize a feature of the teaching and learning context called positionality, which involves locating the self in relation to others within social structures that re-create and mediate those relationships. This approach allows us to see that students' identities are extremely complex and shift depending on context. Attention to positionality requires us to locate our students in relation to one another within a particular set of social structures that govern a particular context. The larger social and ecclesial contexts within which our universities are embedded and which are shaped by heteronormativity, and often also by heterosexism, position the 
Transformative Education in a Broken World: Feminist and Jesuit Pedagogy on the Importance of Context

heterosexual male in a space of relative power and privilege in relation to the gay female, especially in regard to epistemic authority and power to be perceived as a credible interlocutor. So the larger context does not just affect the particular beliefs, perceptions, and values that individual students bring to the (p.170) start of the learning process; it has an impact on the relationships among students in the classroom.

Understanding the positional features of context requires teachers to examine how relationships of domination and subordination between members of oppressed and privileged groups in larger social and ecclesial contexts are re-created at the micro-level in the classroom, and how these relationships affect the acquisition of knowledge, including what views will be taken seriously, who has the authority to speak and be heard, and who has power to cause real moral harm. Accounting for positional features of context involves locating particular perspectives, views, or experiences that students might share in larger historical, cultural, religious, and economic contexts, to understand not only why an individual student may hold a particular view but also how unequal social relationships governing contexts outside the classroom automatically place some students at the center and others at the margins of the classroom.

What feminists draw our attention to is that the nature of oppression is relational and that oppression is manifest in and maintained by broken relationships. If I only focus on how context influences the realities and identities of my students as individuals (i.e., how it affects the beliefs, perceptions, and values each individual student brings to the start of the learning process) but fail to attend to the way context shapes relationships, I am in danger of fostering a classroom atmosphere where the broken relationships that underscore oppressive structures in larger social contexts are replicated and reinforced in the context of my classroom.

To use Young's language, the Jesuit paradigm implies a view of the classroom as an aggregate, or perhaps an association-a space made up of equally situated individuals with different starting points who come together in a classroom setting for sixteen weeks to explore a particular subject together. On the basis of this view, attention to context prompts me to get to know as well as possible each student's starting points. Moreover, from the perspective of viewing the classroom as an association, my response to this incident ought to have been to use this experience as a teachable moment. When a questionable view is put forth in the classroom, we should draw out the reasons for holding the view (p.171) and, as a class, scrutinize the view, exposing whatever flaws in reasoning may be sustaining it. I do think this is a useful strategy in many circumstances, and I also think it is important to attend to individual aspects of our students' identities. But a student got hurt in my classroom. Viewing the classroom as an association of equally situated individuals obscures how social relations of power can be reinforced in our classrooms and cause real harm.

Feminist work on positionality encourages us to see that the social relations of oppression and privilege that inform larger contexts do not disappear when our students enter the classroom. Attention to positionality directs us to view the classroom as comprising social groups, the members of which may be situated in positions of unequal social power. The incident in my classroom was not just about an individual holding and expressing an offensive view; rather, it was a manifestation of the daily realities that many gay men and lesbians experience, which reinforces their marginalization in relation to heterosexual persons and culture. This classroom enactment of oppression reinforced the heterosexism that shaped the context in the first place. Even though I believe I was able to facilitate this young man's reflection on what he had said and why it was harmful, and to see that there is no good evidence to support the view that gay men 
Transformative Education in a Broken World: Feminist and Jesuit Pedagogy on the Importance of Context

and women are pedophiles, I left untouched the relational/positional aspects of the context. Yet it is precisely the relational/positional aspects of the context that help explain, at least in part, the harm this young woman suffered. The young man was not a malicious individual intending to offend, and in the end, he did come to understand why a gay man or lesbian might be offended by his remarks. Yet he had no conception of his positionality in a relative position of privilege and power vis-à-vis this young woman in this context. Interestingly, however, the young woman who was so hurt by this experience understood her positionality quite well. She articulated her constant struggle to be genuinely listened to and heard in the face of stereotypes and prejudices that, from the outset, give her less credibility in public discourse, including classroom settings.

Thinking about positionality also prompted me to ponder my own identity and the social relations that mitigate interactions between me and my students. Both the feminist and Jesuit pedagogy literature tend to be so student focused that they can render the presence of the (p.172) teacher invisible. Yet teachers must also negotiate their identities in the classroom visà-vis their students in order to effectively engage students. This feature of the classroom context became crystal clear for me during this incident. My first response to this incident was to freeze; I was initially immobilized by not knowing how to respond, and I recall feelings of anger and fear. I believe part of my initial reaction had to do with certain positional aspects of my own identity as a young woman in a position (i.e., philosophy professor) still stereotypically associated with men, and as a Catholic and a feminist who often struggles to negotiate these two identities, which are not always obviously compatible. Interestingly, in the end, I believe my identity as a young Catholic and feminist woman played an important role in my ability to relate to both the young man who made the offensive comments and the young woman who was deeply hurt by them. Even though I did not manage at the time to address adequately the relational/ positional aspects of the classroom, upon reflection I came to see that my positional identity did enable me to understand the power relations at work in this context and provide access to relationships of trust that allowed me to engage effectively with both of these students after the fact.

Positionality is an essential component of any approach to education that attempts to transform society by transforming the individual, because it focuses our attention on relationships. The brokenness of our world is, in large part, a function of broken relationships. As we diversify our universities and classrooms, we increasingly invite these broken relationships into the classroom. This is a good thing, but it means that we need to think about how to develop and implement pedagogies that do not inadvertently reinforce those broken relationships. Feminist emphasis on positionality invites us to pay explicit attention to these broken relationships at the micro-level and to devise pedagogies that facilitate students' awareness of their own positional locations.

The classroom setting offers a unique opportunity for students to see where they sit in the larger contexts that generate and perpetuate oppression and injustice in the world and to examine not only how their positionality influences their individual beliefs and perceptions but also how they interact with and treat other people, especially people (p.173) situated on the margins of any particular context. One function of privilege is to make privilege invisible; making relationships of privilege and power visible and coming to know where one is positioned in those relationships are an essential part of transformative education. I believe attention to positionality is an absolutely crucial component of transformative education because transforming the world 
Transformative Education in a Broken World: Feminist and Jesuit Pedagogy on the Importance of Context

requires seeing the ways in which we are part of that which we aim to transform; it more intimately links the personal and the political.

\section{Practical Strategies for and Obstacles to Positional Pedagogies}

I am a philosopher who teaches courses primarily in ethics and feminism, and I am just beginning to think about how to develop and implement positional pedagogies in my classes. One crucial point is that implementing positional pedagogies means going well beyond diversifying the curriculum. Teresa McKenna argues persuasively that diversifying our universities must not be limited to merely incorporating a variety of diverse alternative texts into the curriculum. ${ }^{17}$ As she puts it, "to change the lists is not sufficient. If the subjectivities of teacher and student are not questioned, exposed, integrated into the process of the classroom, then the 'reading' or even 'rereading' of texts will not make a qualitative difference." ${ }^{18}$ In other words, transformative education requires more than simply exposing our students to a new and different angle or perspective on Western culture; it requires that we work toward transforming the broken relationships that sustain injustice and inhibit human flourishing. ${ }^{19}$ Transforming relationships requires engaging with the positional identities of our students and ourselves in any particular classroom context.

Indeed, one crucial part of implementing positional pedagogies involves faculty (not just students) locating their own positional identities in the classroom context. Faculty need to be more self-reflective not only about what teaching methods we aim to employ and which texts we aim to discuss but also about who we are. We need to reflect on our own identities and how these identities position us in the classroom vis-à-vis our students in order to explore what we share with our (p.174) students, our own vulnerability in the classroom, and our own struggles with bias, prejudice, and oppression.

So how can we do this? What I have discovered thus far is that positional pedagogies are radical and that other features of the teaching and learning context present significant barriers or obstacles to implementing them. One way of accounting for positionality in the classroom is through experiential learning. For example, a colleague who teaches graduate-level courses in psychology has a project where students go on public outings holding hands with a member of the same sex. They are asked to pay attention to what the experience feels like, the reactions of others, and so forth. This kind of exercise is certainly an example of a positional pedagogy because it begins to allow students to be explicit about their social identity, the identity of others, and their relationships to those who are members of different social groups. Yet this exercise is radical, requiring a certain level of maturity and openness on the part of students, as well as institutional support that I'm not convinced is readily available for undergraduate courses. This kind of exercise also requires time to process the experience as a class and expertise on the part of the teacher in facilitating fruitful discussions about the exercise.

bell hooks suggests the perhaps less radical strategy of creating space for and assigning real epistemic value to personal confession in the classroom, where all voices are heard and where people share their own experiences publicly. This may be more practicable in most of our classrooms, but in order for this to be effective, students must be willing and able to share their own experiences and, importantly, they must be able to genuinely hear what others share. The goal of positional pedagogies is to draw explicit attention to relationships of power and privilege, and this is risky business. It can be extremely painful for students to have this kind of consciousness-raising experience, and many students are likely to resist the kinds of exercises 
Transformative Education in a Broken World: Feminist and Jesuit Pedagogy on the Importance of Context

that might enable them to move toward this goal. Marquette has a wonderful service-learning program, and I am beginning to think about how service-learning might facilitate positional pedagogies.

Yet there are institutional barriers and other features of the teaching and learning context that make it difficult to implement positional pedagogies, including traditional grading systems, the role of student evaluations in tenure decisions, and concerns about being perceived as (p.175) unfairly biased. For example, a grading system that assigns grades to individuals based on their ability to successfully communicate whatever information they are supposed to know does not easily support the kind of knowledge promoted by positional pedagogies. The traditional grading system cannot easily accommodate learning situations in which students are "learning as a group or learning from each other and not only from the teacher" or are learning about their positionality vis-à-vis others. ${ }^{20}$

Another obstacle is the role of student evaluations in tenure decisions. Positional pedagogies can be painful and uncomfortable as opposed to entertaining or engaging in the way that a really well-put-together lecture might be. bell hooks notes: "I began to see that work to shift paradigms, to change consciousness, cannot necessarily be experienced immediately as fun or positive or safe."21 Often students do not fully understand or appreciate what they've learned until long after the fact, but the initial student scores and comments matter in tenure evaluations, making untenured faculty vulnerable and less free to explore alternative pedagogies.

According to hooks, one helpful strategy when one is implementing a radical pedagogy is to be explicit from the start about the terms of engagement, "to identify what we mean when we say that a course will be taught from a feminist perspective," making the class conscious of what it is they are doing. Can and should we implement positional pedagogies in all our classes, or should they be reserved for courses in certain specialized disciplines or on certain topics for students mature enough to engage in and benefit from them? I have more questions than I do answers. I have come to believe that attention to positionality is an absolutely crucial aspect of transformative education, but knowing how to develop and implement this kind of pedagogy is difficult. This chapter is offered as an attempt to explore precisely how and why an emphasis on positional pedagogy can facilitate the Jesuit mission of transformative education and to prompt further discussion about practical strategies for doing so.

\section{Notes:}

(1.) Frances Maher and Mary Kay Thompson Tetreault, The Feminist Classroom: Dynamics of Gender, Race, and Privilege (Lanham, Md.: Rowman \& Little-field, 2001), chap. 7.

(2.) International Commission on the Apostolate of Jesuit Education, "Ignatian Pedagogy: A Practical Approach, 1993," in The Jesuit "Ratio Studiorum": 400th Anniversary Perspectives, ed. Vincent J. Duminuco (New York: Fordham University Press, 2000), 243.

(3.) Ibid., 247.

(4.) Ibid., 248.

(5.) Ibid. 
Transformative Education in a Broken World: Feminist and Jesuit Pedagogy on the Importance of Context

(6.) In their article on sexism, Ann Cudd and Leslie E. Jones discuss the nature and levels of sexism, and I believe much of their discussion can be applied to the phenomenon of heterosexism too, in particular, their distinction between levels and kinds. See Cudd and Jones, "Sexism," in Feminist Theory: A Philosophical Anthology, ed. Ann Cudd and Robin Andreasen (Oxford: Black-well, 2005), 73-83.

(7.) See Catechism of the Catholic Church (Vatican City: Libreria Editrice Vaticana, 1993), http:// www.vatican.va/archive/catechism/ccc_toc.htm. See pt. 3, sec. 2, chap. 2, especially articles $2332,2357,2358$, and 2359.

(8.) “Vatican to 'Ban New Gay Priests,'” BBC World News, Sept. 2005, http://news.bbc.co.uk/1/hi/ world/europe/4276912.stm.

(9.) bell hooks, "Toward a Revolutionary Feminist Pedagogy," in Falling into Theory: Conflicting Views of Reading Literature (New York: Bedford/St. Martin's Press, 2000), 83.

(10.) Carol Gilligan, In a Different Voice: Psychological Theory and Women's Development (Cambridge, Mass.: Harvard University Press, 1982).

(11.) Nel Noddings and other feminist thinkers developed Gilligan's initial insights into fullblown ethics of care. See Nel Noddings, Caring: A Feminine Approach to Ethics and Moral Education (Berkeley: University of California Press, 1984); Virginia Held, The Ethics of Care: Personal, Political, and Global (New York: Oxford University Press, 2006).

(12.) See Joan Tronto, Moral Boundaries: A Political Argument for an Ethic of Care (New York: Routledge, 1993).

(13.) Iris Marion Young, Justice and the Politics of Difference (Princeton, N.J.: Princeton University Press, 1990), 45, quoting Epstein, "Gay Politics, Ethnic Identity: The Limits of Social Constructionism," Socialist Review 17 (May-Aug. 1987): 9-54.

(14.) Young, Justice, 43.

(15.) Ibid., 93.

(16.) Laurie Finke quoted by Maher and Tetreault, The Feminist Classroom, 64.

(17.) Teresa McKenna, "Borderness and Pedagogy: Exposing Culture in the Classroom," in The Critical Pedagogy Reader, ed. Antonia Darder, Marta Baltodano, and Rodolfo D. Torres (New York: Routledge, 2003), 430-39.

(18.) Ibid., 435.

(19.) Ibid.

(20.) Maher and Tetreault, The Feminist Classroom, 213.

(21.) hooks, "Toward a Revolutionary Feminist Pedagogy," 83. 